\title{
One-stage posterior debridement, bone grafting fusion, and mono-segment vs. short-segment fixation for single-segment lumbar spinal tuberculosis: minimum 5-year follow-up outcomes
}

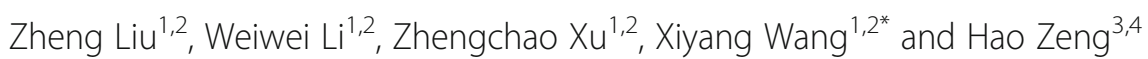

\begin{abstract}
Background: To compare the clinical and radiological outcomes between posterior mono-segment and shortsegment fixation combined with one-stage posterior debridement and bone grafting fusion in treating singlesegment lumbar spinal tuberculosis (LSTB).

Methods: Sixty-two patients with single-segment LSTB treated by a posterior-only approach were divided into two groups: short-segment fixation (Group A, $n=32$ ) and mono-segment fixation (Group B, $n=30$ ). The clinical and radiographic outcomes were analyzed and compared between the two groups.

Results: The intraoperative bleeding volume, operation time, and hospitalization duration were lower in Group B than in Group A. All patients achieved the bony fusion criteria. The visual analog scale score, Japanese Orthopedic Association score, and Oswestry Disability Index were substantially improved 3 months postoperatively and at the last visit in both groups, with no significant difference between the two groups $(P>0.05)$. Kirkaldy-Willis functional evaluation at the final follow-up demonstrated that all patients in both groups achieved excellent or good results. The difference in the angle correction rate and correction loss between Groups A and B was not significant ( $P$ > 0.05).
\end{abstract}

Conclusions: One-stage posterior debridement, bone grafting fusion, and mono-segment or short-segment fixation can provide satisfactory clinical and radiological outcomes. Mono-segment fixation is more suitable for the treatment of single-segment LSTB because the lumbar segments with normal motion can be preserved with less trauma, a shorter operation time, shorter hospitalization, and lower costs.

Keywords: Posterior, Debridement, Fusion, Short-segment fixation, Mono-segment fixation, Single-segment lumbar spinal tuberculosis

\footnotetext{
* Correspondence: 229061878@qq.com

${ }^{1}$ Department of Spine Surgery, Xiangya Hospital, Central South University,

87\#Xiangya Road, Changsha 410008, Hunan, People's Republic of China

${ }^{2}$ Hunan Engineering Laboratory of Advanced Artificial Osteo-materials,

Xiangya Hospital, Central South University, 87\#Xiangya Road, Changsha

410008, Hunan, People's Republic of China

Full list of author information is available at the end of the article
}

(c) The Author(s). 2020 Open Access This article is distributed under the terms of the Creative Commons Attribution 4.0 International License (http://creativecommons.org/licenses/by/4.0/), which permits unrestricted use, distribution, and reproduction in any medium, provided you give appropriate credit to the original author(s) and the source, provide a link to the Creative Commons license, and indicate if changes were made. The Creative Commons Public Domain Dedication waiver (http://creativecommons.org/publicdomain/zero/1.0/) applies to the data made available in this article, unless otherwise stated. 


\section{Background}

According to the latest report by the World Health Organization in 2018 [1], the number of new cases of tuberculosis (TB) worldwide exceeded 10 million and the estimated number of deaths reached 1.6 million in 2017. Among low- to middle-income countries, China ranked second among the 30 countries with the highest TB burden, second only to India.

Spinal TB (STB) is the most frequent and serious form of skeletal TB and can cause vertebral collapse, spinal deformity, neurological injury, and even paraplegia [2, 3]. Conservative treatment with anti-TB chemotherapy is the mainstay of STB therapy [4] and can yield good to excellent clinical outcomes in most patients; however, it cannot prevent kyphotic aggravation. Therefore, medical therapy is the fundamental means of curing musculoskeletal TB, and surgery is an adjunct to anti-TB chemotherapy. Surgery is performed not only to debride the lesion but also to decompress the spinal cord, restore normal spinal alignment, and reconstruct the spinal stability.

In 1911, Hibbs [5] and Albee [6] described posterior fusion as a surgical modality to hasten recovery from TB spondylitis. This approach was later abandoned because posterior fusion did not prevent progressive kyphosis, which could lead to paralysis. This may be due to the lack of strong internal fixation during the early stage of bone fusion, which may lead to poorly effective kyphosis correction and aggravation of kyphosis during the fusion period. A stable, rigid internal fixation system may prevent kyphosis progression and severe back pain caused by spinal instability. With the introduction of screw and rod fixation systems, increasingly more surgeons are adopting the posterior-only approach to treat STB [7-9]. In our previous study [2], we found that in treating thoracolumbar junction STB, long-segment internal fixation with a posterior-only approach prevailed over short-segment fixation in terms of kyphotic correction and maintenance of spinal stability, especially in the long-term prevention of angle loss.

However, because the lumbar area sustains the maximum spinal load and has a high range of motion, the fixation ranges differ between the lumbar and thoracolumbar spine. Because of the anatomic and biomechanical features of the lumbar region, the fixation range and surgical approach in treating lumbar STB (LSTB) are also controversial.

No comparative study has assessed LSTB treated by onestage posterior debridement, fusion, and mono-segment vs. short-segment fixation. Therefore, the present study was performed to compare the clinical and radiological outcomes of posterior mono-segment and short-segment fixation combined with one-stage posterior debridement and bone grafting fusion in treating single-segment LSTB.

\section{Methods}

\section{Basic information}

In total, 76 patients with LSTB and a single-segment lesion who were admitted to our hospital from January 2008 to December 2013 were retrospectively reviewed.

The inclusion criteria were as follows: the main lesion involved a functional unit of the lumbar spine (L2-S1), mono-segment or short-segment fixation was performed by a posterior-only approach, pathological examination revealed a definitive diagnosis of $\mathrm{TB}$, and the patient underwent a minimum 5-year follow-up.

The exclusion criteria were multi-level large paravertebral abscesses or huge iliopsoas abscesses; a history of lumbar surgery and/or other spinal diseases affecting the postoperative evaluation, such as adolescent scoliosis or ankylosing spondylitis; severe vertebral osteoporosis on radiographs; and absence of complete follow-up data for any reason, including loss to follow-up and death.

Based on our previous clinical experience, the indications for surgery were as follows [2]: significant or progressive radiculopathy or cauda equina syndrome due to compression from a TB lesion; severe bone destruction with spinal instability, pathological dislocation, or a developing spinal deformity; a vertebral TB lesion with formation of a large sequestrum or cavity; and persistent back pain resulting from an STB lesion after expectant treatment.

A definitive diagnosis was achieved by pathological examination of the surgically debrided specimen. Four patients in whom spinal TB could not be confirmed by histological examination were excluded from this study. Among the remaining patients, complete follow-up data were available for $62(86 \%)$, and 10 (14\%) were lost to follow-up.

According to the above screening criteria, 62 patients were included in this study and divided into 2 groups according to the fixation range. The short-segment fixation group (Group A) comprised 32 patients (18 male, 14 female) with a mean age of $39.5 \pm 11.6$ years (range, 19-58 years) who underwent one-stage posterior debridement, bone grafting fusion, and short-segment fixation (range to one upper and lower vertebra adjacent to the pathologic segment with/without fixation to the pathologic vertebrae). The mono-segment fixation group (Group B) comprised 30 patients (16 male, 14 female) with a mean age of $42.8 \pm 8.8$ years (range, 18-57 years) who underwent one-stage posterior debridement, bone grafting fusion, and monosegment fixation (range limited to the pathologic segment).

Comprehensive assessment of clinical symptoms, laboratory results, and imaging findings was necessary to diagnose STB [10]. The main clinical symptoms included low back pain, radiating pain, dysesthesia, and dyskinesia of the lower limb. Some patients also had systemic toxicity symptoms such as fever, night sweats, anorexia, and weight loss. No patients had active lung TB or human immunodeficiency virus positivity. The active period of 
TB was confirmed by an increased erythrocyte sedimentation rate (ESR) and C-reactive protein (CRP) concentration in all patients. Imaging examinations were routinely performed. The lumbar imaging findings, such as collapsed vertebrae and necrotic discs, kyphotic deformity, cold abscess formation, and dura compression, were displayed on preoperative radiographs, computed tomography (CT) scans, or magnetic resonance images. The deformity angle was measured by drawing two lines on a lateral image: one on the superior surface of the uppermost-involved vertebra and the other through the inferior surface of lowermost-involved vertebra [11]. Pain severity was evaluated using a visual analog scale (VAS). The Japanese Orthopedic Association (JOA) score [12] and Oswestry Disability Index (ODI) [13] were applied to evaluate dysfunction and quality of life.

\section{Preoperative procedure}

Preoperatively, all patients received standard anti-TB chemotherapy with HRZE for at least 2 weeks, including rifampicin $(450 \mathrm{mg} /$ day), isoniazid ( $300 \mathrm{mg} /$ day), ethambutol $(750 \mathrm{mg} /$ day $)$, and pyrazinamide $(750 \mathrm{mg} /$ day $)$. Surgery was performed when the ESR and CRP concentration had significantly decreased and constitutional symptoms were obviously relieved.

\section{Surgical procedure}

Patients in Group A (Fig. 1) underwent one-stage posterior debridement, bone grafting fusion, and short-segment fixation. Pedicle screws were implanted into the upper and lower vertebra adjacent to the pathologic segment. Whether the screws were fixed to the pathologic vertebrae was based on the extent of vertebral destruction. After installing a temporary internal fixation instrument on the opposite side to avoid nerve injury during contralateral focal debridement, hemi-laminectomy or complete laminectomy was performed on the more severely affected side. The removal of lesions, including TB granulation tissue, caseous necrotic material, sequestra, abscesses, and necrotic discs and endplates, was performed using curettes of different sizes and angles until scraping of the bone surface produced bleeding. By pressurized washing and negative-pressure suction (using a suitable flush tube with saline plunged into the depths of the lesion), all potential residual lesions were debrided as radically as possible.

Before tightening the rods, deformities were corrected by compressing and stretching the internal fixation instrument. An appropriately shaped block-sized allograft or autograft bone was inserted in the interbody to reconstruct the vertebral body. The space between the decorticated transverse processes was carpeted with autogenous or allogeneic particulate bone to promote bone fusion. Local anti-TB therapy with streptomycin (1 $\mathrm{g})$ and isoniazid $(0.3 \mathrm{~g})$ was routinely administered in the surgical area. Drainage was routinely established before suturing the incision closed. Each patient's debrided specimen underwent mycobacterial culture and histopathological examination.
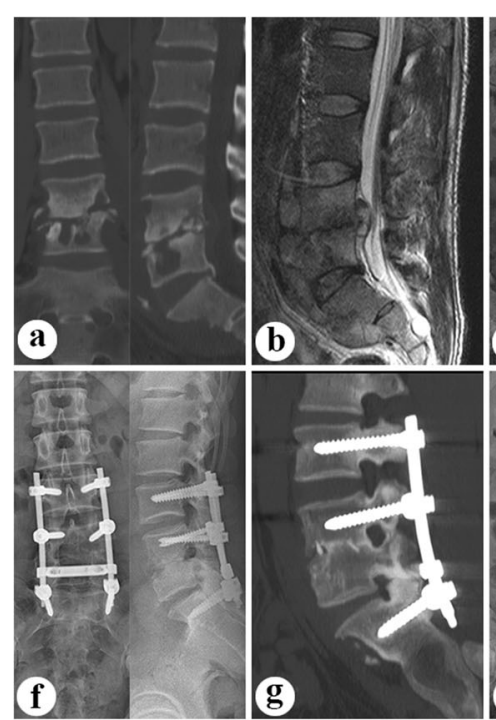
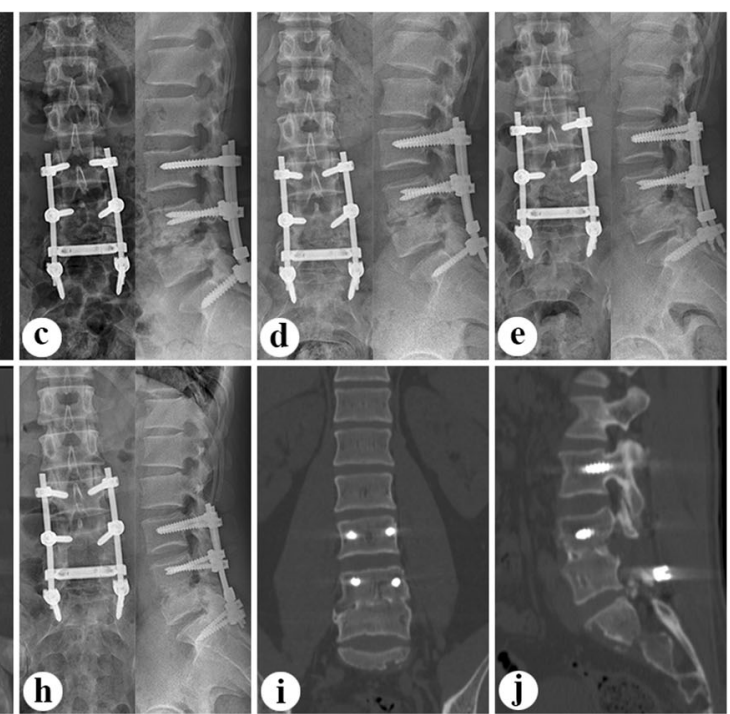

Fig. 1 A patient with L4/5 lesion was performed by one-stage posterior debridement, bone grafting fusion, and short-segment fixation. The preoperative images ((a) CT antero-posterior and lateral, (b) T-2 MRI lateral) showed severe bone destruction, paravertebral abscess formation, dural sac compression and a local lordotic angle $\left(7.4^{\circ}\right)$ at $L 4 / 5$. Postoperative radiography (c) showed that fixation was in good position with an improved local lordotic angle $\left(14.5^{\circ}\right)$. (d) At 3-month after surgery, radiograph presented with interbody bone trabecular formation. During the follow-up, (e) 9-month, (f-g) 24-month after surgery, X-ray or CT displayed solid bone fusion without signs of fixation failure. (i-j) At the last visit (62 month after surgery), radiograph and CT illustrated strong bony fusion and no obvious correction angle loss $\left(1^{\circ}\right)$ with good fixation position 
Patients in Group B (Fig. 2) underwent one-stage posterior debridement, bone grafting fusion, and mono-segment fixation. Pedicle screws were implanted and limited to the pathologic segment. Notably, the screws were located close to the endplates to maintain an adequate distance from the lesion, thus avoiding exposure of the screw after debridement. The other procedures were the same as in Group A.

All operations were performed by the same group of surgeons, and similar implants were used in all procedures.

\section{Postoperative procedure}

The postoperative drainage tube was retained until the drainage flow was $<30 \mathrm{ml} /$ day. Intravenous antiinfection and nutritional agents were routinely administered. A standard anti-TB regimen with HRZE was administered for 3 months. The pyrazinamide was then discontinued, and the HRE chemotherapy was continued for 9 to 15 months. Because of the potential adverse effects of anti-TB drugs, hepatic and renal function was regularly evaluated. Two weeks after surgery, gradual walking was allowed with the aid of a spinal orthosis. During the next 3 to 6 months, the orthosis was removed when interbody bony callus formation was evident on imaging examinations.

\section{Follow-up evaluation}

The ESR and CRP concentration were measured to assess the activity of the TB lesion during the perioperative period and at 3 months postoperatively. During the follow-up, the positions of the graft and instrumentation were investigated by routine radiography or $\mathrm{CT}$, which was also performed to evaluate the graft fusion status during follow-up according to the modified radiological criteria established by Lee et al. [14]. The local deformity angle, JOA score, ODI, and VAS score were recorded preoperatively, postoperatively, and at the final follow-up. At the last visit, the Kirkaldy-Willis functional outcome [15] was used to evaluate the patients' living and working conditions.

\section{Statistical analysis}

The statistical analysis in this study was performed by SPSS 24.0 statistical software (IBM Corp., Armonk, NY, USA). Student's $t$ test was used to compare the clinical data between the two groups. A paired $t$-test was applied to compare the changes in indices in each group preoperatively, postoperatively, and during follow-up. Any discrepancy in the normal distribution was analyzed using the rank sum test. A $P$ value of $<0.05$ was considered statistically significant.

\section{Results \\ Outcomes}

All patients experienced significant improvement in their clinical symptoms after surgery and achieved complete cure during follow-up. The clinical data of the patients in the two groups are shown in Table 1. The intraoperative blood loss volume, operation time, and hospitalization duration were lower in Group B than A $(P<0.05)$. The
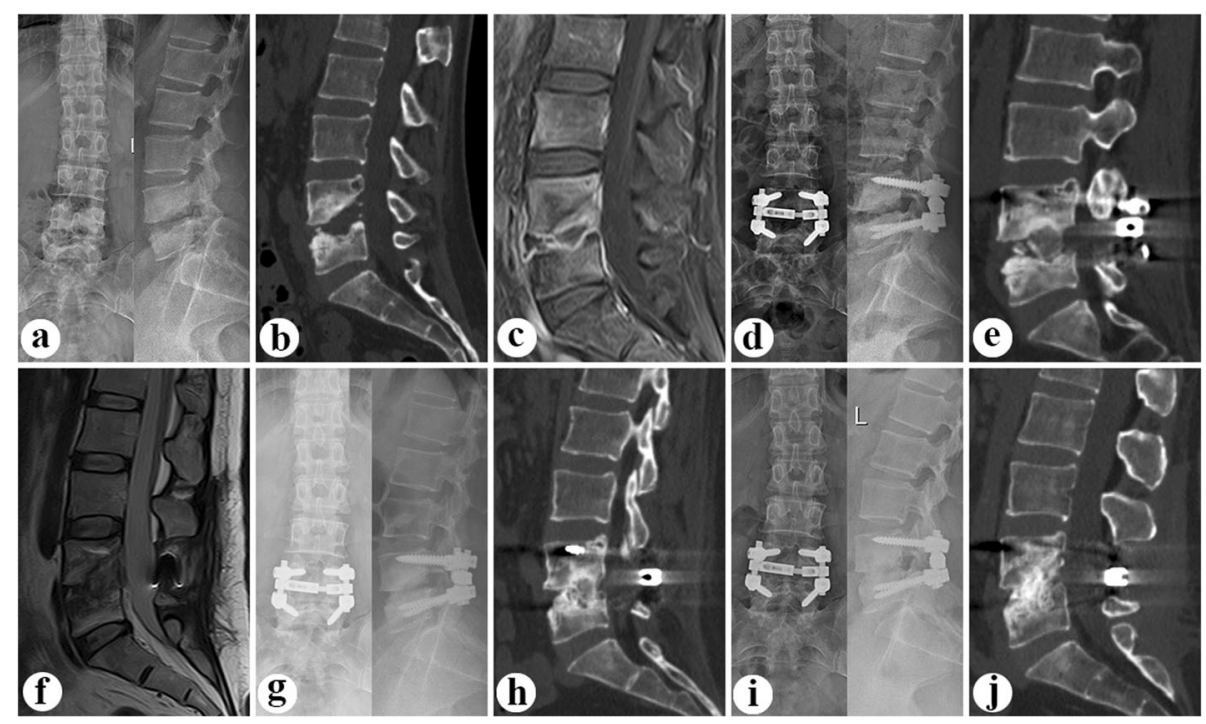

Fig. 2 A patient with L4/5 lesion was performed by one-stage posterior debridement, bone grafting fusion, and mono-segment fixation. The preoperative images ((a) plain antero-posterior and lateral, (b) CT lateral, (c) MRI lateral) illustrated severe vertebral destruction at L4/5 with a local lordotic angle $\left(17^{\circ}\right)$. Postoperative images (d-f) exhibited that internal fixation and implanted bone was in good position with an improved local lordotic angle $\left(23.8^{\circ}\right)$. (g-h) At 11-month after surgery, radiograph and CT showed strong bony fusion at interbody of L4/5. (i-j) At the final followup (64 month after surgery), X-ray and CT demonstrated strong bony fusion and no obvious correction angle loss $\left(0.9^{\circ}\right)$ with good fixation position 
Table 1 The clinical data of patients in two groups

\begin{tabular}{|c|c|c|c|c|}
\hline & $\begin{array}{l}\text { Group A } \\
(N=32)\end{array}$ & $\begin{array}{l}\text { Group B } \\
(N=30)\end{array}$ & $P$-value & Mean $(95 \% \mathrm{Cl})$ \\
\hline Operation time (min) & $162.4 \pm 21.4$ & $137.4 \pm 22.6$ & $0.000<0.05$ & 24.955 \\
\hline Blood loss (ml) & $763.9 \pm 85.9$ & $665.3 \pm 111.9$ & $0.000<0.05$ & 98.538 \\
\hline Hospitalization (days) & $16.5 \pm 2.2$ & $13.6 \pm 2.3$ & $0.000<0.05$ & 2.982 \\
\hline Duration of follow-up (months) & $65.2 \pm 3.7$ & $66.1 \pm 4.5$ & 0.411 & -0.873 \\
\hline Fusion time (months) & $7.9 \pm 1.0$ & $8.2 \pm 1.4$ & 0.296 & -0.330 \\
\hline \multicolumn{5}{|l|}{$\operatorname{ESR}(\mathrm{mm} / \mathrm{h})$} \\
\hline Pre & $68.0 \pm 7.1$ & $67.1 \pm 7.2$ & 0.613 & 0.933 \\
\hline TMP & $9.4 \pm 2.4$ & $9.9 \pm 2.7$ & 0.498 & -0.447 \\
\hline \multicolumn{5}{|l|}{ CRP (mg/l) } \\
\hline Pre & $41.1 \pm 11.9$ & $42.3 \pm 8.4$ & 0.637 & -1.238 \\
\hline TMP & $5.6 \pm 1.7$ & $6.0 \pm 1.7$ & 0.341 & -0.420 \\
\hline
\end{tabular}

Pre preoperative, TMP three months postoperative, FFU final follow-up, $C I$ confidence intervals

mean $95 \%$ confidence intervals were $24.955,98.538$, and 2.982 , respectively.

The differences in the mean follow-up duration and average fusion time were not significant between the two groups $(P>0.05)$. All patients achieved the definitive bony fusion criteria [14] based on radiographic and/or CT assessment. The ESR and CRP level decreased to the reference range in both groups at 3 months postoperatively.

The results of the pain and dysfunction evaluation are presented in Table 2. The VAS score, JOA score, and ODI showed obvious improvement at 3 months postoperatively and the last visit in both groups $(P<0.05)$, and there was no significant difference between the two groups $(P>0.05)$. The Kirkaldy-Willis functional evaluation at the final follow-up demonstrated that all patients in both groups achieved excellent or good results. At the last visit, all patients reported a normal return to their life and work.

Comparison of the local lumbar deformity angle in Groups A and B is shown in Table 3. According to radiographic or CT measurement, 34 patients $\left(\mathrm{A}_{k}\right.$ and $\left.\mathrm{B}_{k}\right)$ had a local lumbar kyphotic angle while 28 patients $\left(\mathrm{A}_{l}\right.$ and $\left.\mathrm{B}_{l}\right)$ had a local lumbar lordotic angle. Groups $A$ and $B$ showed no significant differences in the local lumbar deformity angle preoperatively, immediately postoperatively, or at the last follow-up $(P>0.05)$. In both groups, the local lumbar deformity angle was significantly improved compared with the preoperative angle $(P<0.05)$. The difference in the angle correction rate between Groups A and B was not significant $(P>0.05)$. At the last visit, the mean correction loss was $0.8^{\circ} \pm 0.3^{\circ}$ and $0.9^{\circ} \pm 0.3^{\circ}$ in Group $A_{k}$ and $\mathrm{B}_{k}(P>0.05)$ and $0.7^{\circ} \pm 0.3^{\circ}$ and $0.6^{\circ} \pm 0.2^{\circ}$ in Group $\mathrm{A}_{l}$ and $\mathrm{B}_{l}(P>0.05)$, respectively.

\section{Complications}

Postoperative complications occurred in both groups. Two patients in Group A and one patient in Group B developed a superficial wound infection that healed with anti-infection agents and wound dressings. One patient in each group developed cerebrospinal fluid leakage, which was cured by leaving the drainage tube in place longer and increasing the fluid therapy. One patient in Group B developed liver function damage induced by anti-TB drugs; this patient was treated with modified chemotherapy combined with hepatic protection drugs. No complications related to internal fixation occurred in either group during follow-up.

\section{Discussion \\ Characteristics of LSTB}

The lumbar region sustains the largest load and exhibits the greatest mobility among all spinal regions. Because of the large pressure and shear force on the lumbar

Table 2 The evaluation outcomes of pain and dysfunction

\begin{tabular}{|c|c|c|c|c|c|c|c|c|c|c|c|c|c|}
\hline \multirow[t]{2}{*}{ Group (n) } & \multicolumn{3}{|l|}{ VAS } & \multicolumn{3}{|l|}{ JOA } & \multicolumn{3}{|l|}{ ODI } & \multicolumn{4}{|c|}{ Kirkaldy-Willis criteria } \\
\hline & Pre & TMP & FFU & Pre & TMP & FFU & Pre & TMP & FFU & $E$ & G & $F$ & $P$ \\
\hline A (32) & $7.6 \pm 0.9$ & $2.5 \pm 0.6$ & $0.9 \pm 0.6$ & $12.5 \pm 2.7$ & $17.3 \pm 3.0$ & $25.4 \pm 2.5$ & $37.9 \pm 4.8$ & $17.6 \pm 3.5$ & $7.1 \pm 2.0$ & 20 & 12 & 0 & 0 \\
\hline B (30) & $7.6 \pm 1.1$ & $2.6 \pm 0.6$ & $0.9 \pm 0.6$ & $12.9 \pm 2.9$ & $17.5 \pm 3.3$ & $25.9 \pm 2.6$ & $36.8 \pm 5.2$ & $17.1 \pm 3.3$ & $7.4 \pm 1.7$ & 22 & 8 & 0 & 0 \\
\hline P-value & 0.942 & 0.591 & 0.641 & 0.530 & 0.736 & 0.404 & 0.395 & 0.580 & 0.574 & & & & \\
\hline Mean $(95 \% \mathrm{Cl})$ & -0.019 & -0.083 & 0.069 & -0.449 & -0.275 & -0.545 & 1.103 & 0.481 & -0.271 & & & & \\
\hline
\end{tabular}

Pre preoperative, TMP three months postoperative, FFU final follow-up, $E$ excellent, $G$ good, $F$ fair, $P$ poor, $C l$ confidence intervals 
Table 3 Comparison of the local lumbar deformity angle

\begin{tabular}{|c|c|c|c|c|c|c|c|}
\hline \multirow[t]{2}{*}{ Group } & \multirow[t]{2}{*}{$n$} & \multicolumn{3}{|c|}{ Kyphosis angle $\left({ }^{\circ}\right)$} & \multicolumn{2}{|c|}{ Angle correction } & \multirow[t]{2}{*}{ Correction loss $\left({ }^{\circ}\right)$} \\
\hline & & Pre & Post & FFU & Post $\left(^{\circ}\right)$ & Rate (\%) & \\
\hline$A_{k}$ & 20 & $18.4 \pm 6.8$ & $5.4 \pm 1.7$ & $6.2 \pm 1.7$ & $12.8 \pm 5.7$ & $68.1 \pm 9.7$ & $0.8 \pm 0.3$ \\
\hline $\mathrm{B}_{k}$ & 14 & $18.0 \pm 6.7$ & $5.6 \pm 1.6$ & $6.5 \pm 1.6$ & $12.4 \pm 5.4$ & $66.9 \pm 6.2$ & $0.9 \pm 0.3$ \\
\hline$P$-value & & $P=0.866$ & $P=0.702$ & $P=0.699$ & $P=0.810$ & $P=0.699$ & $P=0.776$ \\
\hline \multirow[t]{3}{*}{ Mean (95\% Cl) } & & 0.404 & -0.219 & -0.246 & 0.473 & 1.149 & -0.026 \\
\hline & & \multicolumn{3}{|c|}{ Lordotic angle $\left({ }^{\circ}\right)$} & & & \\
\hline & & Pre & Post & FFU & & & \\
\hline$A_{l}$ & 12 & $10.0 \pm 5.5$ & $18.7 \pm 4.9$ & $18.0 \pm 4.9$ & $8.6 \pm 2.5$ & $46.3 \pm 22.4$ & $0.7 \pm 0.3$ \\
\hline $\mathrm{B}_{1}$ & 16 & $10.5 \pm 5.3$ & $19.0 \pm 3.8$ & $18.5 \pm 3.8$ & $8.5 \pm 2.2$ & $48.1 \pm 19.2$ & $0.6 \pm 0.2$ \\
\hline$P$-value & & $P=0.815$ & $P=0.822$ & $P=0.778$ & $P=0.909$ & $P=0.823$ & $P=0.289$ \\
\hline Mean $(95 \% \mathrm{Cl})$ & & -0.488 & -0.375 & -0.477 & 0.102 & -1.783 & 0.102 \\
\hline
\end{tabular}

Pre preoperative, post postoperative immediately, FFU final follow-up, Cl confidence intervals

$A_{k}$ and $B_{k}$ : the cases with a local lumbar kyphosis angle in lesions

$A_{\text {/ }}$ and $B_{\text {; }}$ the cases with a local lumbar lordotic angle in lesions

segments, lumbar stability is maintained by the combined effects of the vertebrae, intervertebral discs, rich muscle groups, and tough ligaments. The local anatomical structures adjacent to the lumbar region are complex and include major blood vessels, nerves, and the ureters.

LSTB mainly involves the anterior and middle lumbar columns, potentially leading to vertebral destruction and collapse, changes in the physiological lordosis and load biomechanics, kyphosis deformity, and protrusion of the pathological tissues into the vertebral canal, seriously affecting patients' health and quality of life. LSTB usually presents with low back pain with or without radicular leg pain and neurologic deficits secondary to compression of the cauda equina and nerve roots.

\section{Importance of posterior-only approach}

Surgical procedures in the posterior-only approach, including lesion debridement and bone grafting and fixation, can be accomplished simultaneously using one incision without changing the position; thus, this approach is much less invasive than others. Additionally, the posterior-only approach is familiar to spinal surgeons and avoids possible injury to the large blood vessels, nerves, or other anatomical structures. Furthermore, internal fixation in the posterior-only approach is more effective than that in the anterior approach with respect to kyphotic correction and the maintenance of correction [16].

However, many surgeons are concerned about the potential increase in spinal instability caused by damage to the posterior column. In our experience, the strong threecolumn fixation can effectively maintain short-term postoperative spinal stability. Furthermore, strong bony fusion can be obtained by the combination of interbody bone grafting and lateral bone grafting or posterior lamina reconstruction, maintaining long-term spinal stability.
The concentration of TB lesions mainly in the anterior column has given rise to controversy regarding whether the posterior approach can completely achieve focal debridement. Indeed, the posterior-only approach offers no advantage with respect to debridement. However, removal of the lamina and facet joints with moderate stretching of the nerve roots and dura mater can provide adequate surgical space in which $360^{\circ}$ lesion debridement under direct vision can be achieved. Moreover, subsequent procedures, including saline irrigation at the lesion site with pressurized washing and negativepressure suction and postoperative postural drainage, can effectively drain pus and eliminate residual lesions [17]. Furthermore, the cleared lesion can facilitate the penetration of anti-TB drugs, improving the efficacy of local anti-TB drugs intraoperatively and systemic antiTB drugs postoperatively and resulting in cure through spontaneous fusion in STB lesions. Therefore, complete debridement need not be overemphasized [18].

\section{Choice of fixation range}

The choice of the fixed segment range is the focus of long-standing debate in lumbar fixation. In this study, the fixed range of mono-segment fixation was limited to the pathologic segment. Short-segment fixation is defined as limitation of the fixed range to one upper and lower vertebra adjacent to the pathologic segment, with or without inclusion of the pathologic segment according the extent of the vertebral destruction.

Short-segment fixation [19] provides strong fixation and deformity correction and is still applied by most surgeons for treatment of single-segment LSTB. The increase in the fixed segment range can distribute the longitudinal stress of the spine to longer segments, which can significantly maintain the spinal stability, improve the vertebral body height, and prevent loss of the 
correction angle. However, short-segment fixation also sacrifices the motion of the two normal segments, affecting the activity of the lumbar spine in the long term and leading to aggravation of adjacent segment degeneration (ASD), which may ultimately induce ASD-related diseases [20]. One study [21] showed that longer fixed segments result in greater stress concentration and exert greater loads on adjacent segments, which may accelerate ASD and cause lower back pain, pseudarthrosis, and implant rupture.

Because of the anatomical features and high requirement of activity in the lumbar region, preserving segments with normal motion is important to ensure high long-term quality of life. Thus, mono-segment rather than short-segment fixation is superior for LSTB. However, many surgeons are concerned that mono-segment fixation cannot meet the requirements of reconstruction stability in treating STB. In this study, we compared the clinical and radiological outcomes of posterior shortsegment versus mono-segment fixation combined with one-stage posterior debridement and bone grafting fusion in treating single-segment LSTB.

Maida et al. [22] compared the clinical and radiological outcomes of mono-segment fixation with bi-segment fixation in treating thoracolumbar spine fractures. They found no statistically significant difference in vertebral body height restoration or correction of the kyphotic deformity between the two groups, confirming the validity of mono-segment fixation. Wei et al. [23] demonstrated that both monosegment fixation and short-segment fixation are effective and reliable for thoracolumbar burst fractures. Monosegment fixation significantly shortened the operative time and decreased the amount of blood loss, thus offering better clinical results. Li et al. [24] reported that the mean postoperative VAS score and vertebral kyphotic angle were similar in the mono-segment fixation group and shortsegment fixation group. These clinical studies have demonstrated that mono-segment fixation can meet the stability requirements necessary for spinal fracture reconstruction, which has also been confirmed in biomechanical experiments and finite element analysis [25, 26].

Various degrees of reactive new bone formation can be seen in the involved vertebrae in most patients with STB. The vertebrae involved by Mycobacterium tuberculosis form sclerotic bone walls, resulting in abnormally high bone density of the pathological vertebrae. This pathologic feature of STB brings stronger holding forces of the pedicle screws to the involved vertebrae than in spinal fracture, making mono-segment fixation more feasible for treating STB than spinal fractures. Wang et al. [27] reported that after bone fusion, mono-segment fixation was effective in restoring and maintaining spinal stability and retained normal-motion segments more than did shortsegment fixation.
In the present study, the mean local angle correction rate and correction loss were $66.9 \% \pm 6.2 \%$ and $0.9^{\circ} \pm$ $0.3^{\circ}$ in Group $B_{k}$ and $48.1 \% \pm 19.2 \%$ and $0.6^{\circ} \pm 0.2^{\circ}$ in Group $\mathrm{B}_{l}$, respectively. There were no differences in the deformity angle correction rate or correction loss between Groups A and B $(P>0.05)$. These findings indicate that mono-segment fixation can achieve satisfactory effectiveness in restoring and maintaining spinal stability, similar to short-segment fixation.

Mono-segment fixation has several advantages in treating single-segment LSTB. Above all, the lumbar segments with normal motion can be retained, which may slow the degeneration of adjacent segments to some extent. Additionally, the surgical field of exposure in mono-segment fixation is relatively smaller and less invasive. Furthermore, the need for fewer fixation materials reduces the operation time and hospitalization costs, which can ease the burden on patients and may be more suitable for patients in developing countries and poorer areas. In the present study, the mean operative time, amount of blood loss, and hospitalization duration in Group B were 137.4 \pm 22.6 min, $665.3 \pm 111.9$ $\mathrm{ml}$, and $13.6 \pm 2.3$ days respectively, all of which were lower than those in Group A $(P<0.05)$.

The application of mono-segment fixation in treating single-segment LSTB also has some limitations. Because of the irregular destruction created by LSTB, the degree of vertebral destruction varies among different patients. The choice for mono-segment fixation should be based on the extent of vertebral destruction. Wang et al. [28] considered that the remaining one- to two-thirds of the vertebral height is enough to accommodate a conventional transpedicular screw after debridement, which is consistent with our experience. In addition, the structural integrity, including the pedicle in the diseased vertebrae, the upper endplate of the upper pathologic vertebra, and the lower endplate of the lower pathologic vertebra, are important for screw implantation.

Therefore, mono-segment fixation can be chosen when the following two conditions are fulfilled: a major lesion involving one motion unit of the lumbar spine is present, and enough space is available for screw implantation in the vertebrae adjacent to the lesion (more than one-third the vertebral height, with structural integrity of the pedicle and endplates in the pathologic vertebrae). Furthermore, mono-segment fixation is unsuitable for patients with severe kyphosis deformity or osteoporosis. Short-segment fixation is more suitable when the pathologic vertebral height is less than one-third.

This study has two main limitations. First, its retrospective nature may have resulted in biased outcomes. Second, the sample size was relatively small and the follow-up duration was relatively short. Therefore, prospective studies with larger samples and longer followup periods are needed. 


\section{Conclusions}

Either one-stage posterior debridement, bone grafting fusion, and mono-segment or short-segment fixation can achieve satisfactory clinical and radiological outcomes. However, mono-segment fixation is more suitable in treating single-segment LSTB because the lumbar segments with normal motion can be preserved with less trauma, a shorter operation time, shorter hospitalization, and lower costs.

\author{
Abbreviations \\ CRP: C-reactive protein; CT: Computed tomography; ESR: Erythrocyte \\ sedimentation rate; JOA: Japanese Orthopaedic Association; LSTB: Lumbar \\ spinal tuberculosis; ODI: Oswestry-Disability index; STB: Spinal tuberculosis; \\ TB: Tuberculosis; VAS: Visual analogue scale
}

\section{Acknowledgements}

Not applicable.

\section{Authors' contributions}

ZL participated in the design of this study and performed the statistical analysis. ZL drafted the manuscript. WL, ZX and HZ collected the clinical data and follow-up details of this study, and XW participated in the study design and helped to draft the manuscript. All authors read and approved the final manuscript.

\section{Funding}

This study was supported by the National Natural Science Foundation of China (No.81672191), Clinical Scientific Research Funds of Xiangya Hospital (2016 L07), the Fundamental Research Funds for the Central Universities of Central South University (2019zzts336), Young Scientist Fund of Guangxi Medical University (Grant No.GXMUYSF201701) and Natural Science Fund of Guangxi Zhuang Autonomous Region (Grant No. 2018JJB140199). No benefit in any form has been or will be received from a commercial party related directly or indirectly to the subject of this manuscript.

\section{Availability of data and material}

The datasets generated and/or analyzed during the current study are available from the corresponding author on reasonable request.

\section{Ethics approval and consent to participate}

The study protocol was approved by the Ethics Committee of Xiangya Hospital and written informed consent were obtained from all patients.

\section{Consent for publication}

Not applicable.

\section{Competing interests}

The authors declare that they have no competing interests.

\begin{abstract}
Author details
${ }^{1}$ Department of Spine Surgery, Xiangya Hospital, Central South University, 87\#Xiangya Road, Changsha 410008, Hunan, People's Republic of China. ${ }^{2}$ Hunan Engineering Laboratory of Advanced Artificial Osteo-materials, Xiangya Hospital, Central South University, 87\#Xiangya Road, Changsha 410008, Hunan, People's Republic of China. ${ }^{3}$ Department of Spinal Surgery, the First Affiliated Hospital of Guangxi Medical University, No. 6 Shuangyong Rd, Nanning 530021, Guangxi, China. ${ }^{4}$ Guangxi Key Laboratory of Regenerative Medicine, Nanning 530021, Guangxi, China.
\end{abstract}

Received: 1 November 2019 Accepted: 3 February 2020 Published online: 07 February 2020

\section{References}

1. World Health Organization. Global tuberculosis report 2018. Available from: http://www.who.int/tb/publications/global_report/en/. 2018.

2. Liu Z, Zhang $P$, Zeng $H, X u Z$, Wang X. A comparative study of single-stage transpedicular debridement, fusion, and posterior long-segment versus short-segment fixation for the treatment of thoracolumbar spinal tuberculosis in adults: minimum five year follow-up outcomes. Int Orthop. 2018;42(4):1-8.

3. Liu Z, Wang $X, X u Z$, Zeng H, Zhang P, Peng W, Zhang Y. Two approaches for treating upper thoracic spinal tuberculosis with neurological deficits in the elderly: a retrospective case-control study. Clin Neurol Neurosurg. 2016; 141:111-6.

4. Moon MS, Moon YW, Moon JL, Kim SS, Sun DH. Conservative treatment of tuberculosis of the lumbar and lumbosacral spine. Clin Orthop Relat Res. 2002;398(398):40-9.

5. Hibbs RA. An operation for progressive spinal deformities: a preliminary report of three cases from the service of the orthopaedic hospital. 1911 Clin Orthop Relat Res. 2007;93(35):17-20.

6. Albee FH. Transplantation of a portion of the tibia into the spine for Pott's disease: a preliminary report 1911. Clin Orthop Relat Res. 2007;57(4):14-6.

7. Wang LJ, Zhang HQ, Tang MX, Gao QL, Zhou ZH, Yin XH. Comparison of three surgical approaches for thoracic spinal tuberculosis in adult: minimum 5-year follow up. Spine. 2017;42(11):808-17.

8. Zhang P, Wei P, Wang X, Luo C, Xu Z, Hao Z, Zheng L, Zhang Y, Lei G. Minimum 5-year follow-up outcomes for single-stage transpedicular debridement, posterior instrumentation and fusion in the management of thoracic and thoracolumbar spinal tuberculosis in adults. Br J Neurosurg. 2016:1-6.

9. Wang $Y X$, Zhang HQ, Liao W, M-x T, C-f G, Deng A, Wu JH, Liu JY. One-stage posterior focus debridement, interbody graft using titanium mesh cages, posterior instrumentation and fusion in the surgical treatment of lumbosacral spinal tuberculosis in the aged. Int Orthop. 2016;40(6):1117-24.

10. Liu Z, Wang J, Chen G-Z, Li W-W, Wu Y-Q, Xiao X, Zhang Y-L, Yang Y, Hu WK, Sun Z-C, et al. Clinical characteristics of 1378 inpatients with spinal tuberculosis in general hospitals in south-Central China. Biomed Res Int. 2019;2019:11.

11. Bezer M, Kucukdurmaz FN, Kocaoglu B, Guven O. Tuberculous spondylitis of the lumbosacral region: long-term follow-up of patients treated by chemotherapy, transpedicular drainage, posterior instrumentation, and fusion. J Spinal Disord Tech. 2005;18(5):425.

12. Azimi P, Mohammadi HR, Montazeri A. An outcome measure of functionality and pain in patients with lumbar disc herniation: a validation study of the Japanese orthopedic association (JOA) score. J Orthop Sci. 2012:17(4):341-5.

13. van Hooff ML, Spruit M, Fairbank JC, Van LJ, Jacobs WC. The Oswestry disability index (version 2.1a): validation of a Dutch language version. Spine. 2015;40(2):83-90.

14. Lee CK, Vessa P, Lee JK. Chronic disabling low back pain syndrome caused by internal disc derangements. The results of disc excision and posterior lumbar interbody fusion. Spine. 1995;20(3):356-61.

15. Nowakowski P, Delitto A, Erhard RE. Lumbar spinal stenosis. Clin Orthop Relat Res. 1996;76(2):187.

16. Ma YZ, Cui X, Li HW, Chen X, Cai XJ, Bai YB. Outcomes of anterior and posterior instrumentation under different surgical procedures for treating thoracic and lumbar spinal tuberculosis in adults. Int Orthop. 2012;36(2): 299-305.

17. Pang $X$, Shen $X$, Wu P, Luo C, Xu Z, Wang X. Thoracolumbar spinal tuberculosis with psoas abscesses treated by one-stage posterior transforaminal lumbar debridement, interbody fusion, posterior instrumentation, and postural drainage. Arch Orthop Trauma Surg. 2013; 133(6):765-72.

18. Xu Z, Wang X, Shen X, Luo C, Zeng H, Zhang P, Peng W. Posterior only versus combined posterior and anterior approaches for lower lumbar tuberculous spondylitis with neurological deficits in the aged. Spinal Cord. 2015:53(6):482-7.

19. Shen X, Liu H, Wang G, Pang X, Luo C, Zeng H, Xu Z. The role of singlestage posterior debridement, interbody fusion with titanium mesh cages and short-segment instrumentation in thoracic and lumbar spinal tuberculosis. J Neurosurg Sci. 2015

20. Maruenda JI, Barrios C, Garibo F, Maruenda B. Adjacent segment degeneration and revision surgery after circumferential lumbar fusion: outcomes throughout 15 years of follow-up. Eur Spine J. 2016;25(5): 1550-7.

21. Sudo H, Oda I, Abumi K, Ito M, Kotani Y, Minami A. Biomechanical study on the effect of five different lumbar reconstruction techniques on adjacentlevel intradiscal pressure and lamina strain. J Neurosurg Spine. 2006:5(2): 150-5. 
22. Maida GAL, Luceri F, Ferraro M, Ruosi C, Mineo GV, Misaggi B. Monosegmental vs bisegmental pedicle fixation for the treatment of thoracolumbar spine fractures. Inj Int J Care Injured. 2016;47:S35-43.

23. Fu-Xin W, Shao-Yu L, Chun-Xiang L, Hao-Miao L, Hou-Qing L, Bin-Sheng Y, Bai-Ling C, Ke-Bing C. Transpedicular fixation in management of thoracolumbar burst fractures: monosegmental fixation versus shortsegment instrumentation. Spine. 2010;35(15):E714.

24. Li X, Ma Y, Dong J, Li J. Retrospective analysis of treatment of thoracolumbar burst fracture using mono-segment pedicle instrumentation compared with short-segment pedicle instrumentation. Eur Spine J. 2012; 21(10):2034-42.

25. Markus S, Erich H, Michael S, Lothar K, Lutz C, Hans-Joachim W. Biomechanical in vitro comparison of different mono- and bisegmental anterior procedures with regard to the strategy for fracture stabilisation using minimally invasive techniques. Eur Spine J. 2006;15(1):90-4.

26. Zander T, Rohlmann A, Klockner C, Bergmann G. Comparison of the mechanical behavior of the lumbar spine following mono- and bisegmental stabilization. Clin Biomech. 2002;17(6):439-45.

27. Wang Z, Wu Q, Geng G. Anterior debridement and bone grafting with posterior single-segment internal fixation for the treatment of monosegmental spinal tuberculosis. Inj Int J Care Injured. 2013;44(2):253-7.

28. Wang Z, Yuan H, Shi J, Jin W. Posterior mono-segmental fixation, combined with anterior debridement and strut graft, for treatment of the monosegmental lumbar spine tuberculosis. Int Orthop. 2012;36(2):325-9.

\section{Publisher's Note}

Springer Nature remains neutral with regard to jurisdictional claims in published maps and institutional affiliations.

Ready to submit your research? Choose BMC and benefit from:

- fast, convenient online submission

- thorough peer review by experienced researchers in your field

- rapid publication on acceptance

- support for research data, including large and complex data types

- gold Open Access which fosters wider collaboration and increased citations

- maximum visibility for your research: over $100 \mathrm{M}$ website views per year

At $\mathrm{BMC}$, research is always in progress.

Learn more biomedcentral.com/submissions 